\title{
TEORÍA DEL ACTO JURÍDICO Y CONCEPTO DEL NEGOCIO JURÍDICO
}

\author{
Luz Gladys Rogue Montesillo*
}

\begin{abstract}
Resumen
El artículo tiene la finalidad de hacer conocer la teoría del acto jurídico y el concepto y contenido del negocio jurídico en relación con el artículo $140^{\circ}$ del Código Civil Peruano.

Se avoca a realizar un planteamiento para establecer que concepción debe seguir la norma sustantiva civil, debiendo tener en cuenta la realidad social de cada ordenamiento jurídico.
\end{abstract}

Palabras clave: Acto jurídico - negocio jurídico - hecho jurídico.

\begin{abstract}
This article has the purpose of making the theory of the legal transaction known, as well as the concept and the content of the legal business in relation to the article $140^{\circ}$ of the Peruvian Civil Code.

It aim to realize an exposition to establish which conception must be followed by the substantive civilian norm, having to consider the social reality of each legal ordering.
\end{abstract}

Key words: Legal transaction - legal business - egal fact.

\section{Sumario}

1. Introducción. 2. La teoría del acto jurídico y concepto del negocio jurídico. 3. El acto jurídico. 4. Negocio jurídico.

\footnotetext{
* Vocal Titular de la Corte Superior de Justicia de Cañete - Poder Judicial de Perú.
} 


\section{INTRODUCCIÓN}

El fenómeno del acto jurídico, al igual que el contrato, están basados o fundamentados en la necesidad de explicar y entender adecuadamente cuándo las intenciones de los sujetos de derechos, en un determinado ordenamiento jurídico, en una sociedad y en un momento histórico determinado, deben ser valoradas y tomadas en consideración por dicho ordenamiento para la atribución de efectos jurídicos ${ }^{1}$.

\section{LA TEORÍA DEL ACTO JURÍDICO Y CONCEPTO DEL NEGOCIO JURÍDICO}

\subsection{Código de Francia}

Estamos frente a una concepción completamente individualista y artificial de los comportamientos del hombre que producen consecuencias legales; "individualistas" porque se deja de lado toda valoración social y normativa, y "artificial" porque se pretende hacer creer que es en la voluntad del individuo donde reposa la esencia del concepto mismo de acto jurídico.

Como veremos más delante, es justamente ésta concepción abstracta y artificial, lo que ha originado en nuestro medio, cierto rechazo al estudio de la doctrina general del acto jurídico; es decir, por pensar que se trata de un asunto meramente académico, puramente abstracto y de ninguna aplicación práctica.

Pothier, señala que por objeto del contrato debe entenderse el objeto de la obligación que constituye la prestación estipulada por una de las partes y prometida por otra; y así lo entienden en general los comentadores del Code (Mercadé, Demolombe, Laurent, Baudry-Lacantinerie, Capitant, etcétera).Como es sabido, los autoresclásicos fueron los primeroscomentaristas del Código Civil Francés, quienes se basaron en las ideas expuestas por Domat y Pothier.

Las obras doctrinarias de estos dos grandes civilistas del antiguo Derecho Francés fueron el reflejo de la corriente del pensamiento predominante en la época; nos estamos refiriendo al "iusnaturalismo" que resalto en todo momento como valor fundamental "la libertad del hombre", entendiendo a éste último como el centro de la sociedad y por ende el centro del ordenamiento jurídico, cuya función debe limitarse en último término a consagrar todos los propósito de los sujetos de derecho. 
Corresponde pues, a esta época la idea del denominado "dogma de la voluntad", en el sentido que el Derecho tiene como función la de recoger las aspiraciones de los sujetos y darles protección legal. De ahí se derivaron como algo natural los principios de la "autonomía de la voluntad", del simple "consensualismo", del "valor de la palabra dada", y todos aquellos principios jurídicos que tienen como común denominador el resaltar el valor de la voluntad como fuente de derechos y obligaciones en el ordenamiento jurídico, correspondiendo a este último, como ya se ha indicado, únicamente el recibir las expresiones de voluntad de los sujetos y conceder en lógica correspondencia los efectos jurídicos perseguidos, siempre y cuando, claro está, no convengan los principios y valores que conforman el orden público y las buenas costumbre, entendidas como reglas de convivencia social aceptadas por todos los miembros de una determinada comunidad, como de cumplimiento obligatorio, o normas imperativas.

Dentro de la concepción iusnaturalista del derecho², es lógico pensar que se definan los actos del hombre relevante jurídicamente como simples manifestaciones de voluntad dirigidas a la producción de efectos jurídicos, sin tomar en cuenta en absoluto la función organizadora y ordenadora del ordenamiento jurídico pues siendo el hombre el centro del sistema jurídico, nada más fácil y consecuente resulta concebir el acto jurídico como una simple manifestación de voluntad o la expresión de un deseo, pero de producir consecuencias jurídicas.

Como se podrá apreciar, el fenómeno del acto jurídico, al igual que el contrato, están basados o fundamentados en la necesidad de explicar y entender adecuadamente, cuando las intenciones de los sujetos de derechos, en un determinado ordenamiento jurídico y en una sociedad y en un momento histórico determinado deben ser valoradas y tomadas en consideración por dicho ordenamiento jurídico para la atribución de efectos jurídicos, porque se trata de diferencias, dentro de todos los comportamientos del hombre, en el ámbito social los que deben merecer la tutela legal en atención al propósito práctico que los hubiera determinado, con la consiguiente imposibilidad de retractarse, de aquellos otros que son intranscendentes, o que siendo también relevante jurídicamente, producen efectos atribuidos directa y abstractamente por la norma jurídica al simple comportamiento voluntario sin interesar el fin práctico perseguido por sus autores.

Habiendo llegado algunos a plantear, copiando ideas de autores extranjeros, el que deba prescindirse de toda referencia al acto jurídico dentro del Código Civil Peruano, pues bastaría la noción genérica del contrato para resolver los problemas que sugiere y plantea la teoría general del acto jurídico. 
Posición que comparto igual que Lizardo Taboada Córdova, que desde nuestro punto de vista, es completamente equivocada y que responde en gran medida a la costumbre, muy arraigada en algunos sectores de nuestro medio jurídico, de copiar y aceptar sin discusión algunos preceptos doctrinarios de autores extranjeros de gran prestigio. Esta posición, felizmente minoritaria, olvida que el acto jurídico, además de un problema teórico es también una opción legal, sin embargo, sobre este aspecto, volveremos nuevamente más adelante.

\section{El Código Alemán}

Ahora bien, una vez creado este concepto por los autores clásicos franceses y difundido a nivel doctrinario con mucha fuerza, en Alemania, desde antes de la promulgación del Código Civil Alemán y con mayor razón a partir de la entrada en vigencia en 1900, los pandectistas, ante la necesidad igual dejustificar y conceptualizar los actos del hombre que son relevantes jurídicamente, por una diversa interpretación de las fuentes, crearon y elaboraron el concepto de "negocio jurídico", que en su primera versión, clásica pandectista, coincidió totalmente con la versión clásica francesa, salvo el cambio de término, mientras los "clásicos franceses" prefirieron la denominación de "acto jurídico, los pandectista optaron por el "negocio jurídico", pero coincidiendo totalmente en los postulados, pues entendieron y definieron el negocio jurídico al igual que los franceses, como una declaración de voluntad que produce efectos jurídicos perseguidos por los sujetos como jurídicos precisamente.

2.2. La Doctrina Contemporánea desarrolló la Teoría del Negocio Jurídico, uno de los principales representantes fue el Código Civil Alemán de 1900 BCG:

Primero: la doctrina alemana elaboró la teoría del negocio jurídico, esta doctrina señala que el "negocio" es una declaración de voluntad orientada a conseguir una finalidad práctica lícita amparada por el ordenamiento legal, esta definición la saca de los pandectistas alemanes. ${ }^{3}$

Los pandectistas ante la necesidad de justificar y conceptualizar los actos del hombreque son relevantes jurídicamente crearon y elaboraron el concepto del "negocio jurídico ", que en su primera versión clásica pandectista coincidió totalmente con la versión clásica francesa, salvo el cambio de termino, pues mientras los clásicos franceses prefirieron la denominación de "acto jurídico" los pandectistas optaron por la de " negocio jurídico", pero coincidiendo totalmente en sus postulados, pues entendieron y definieron al negocio 
jurídico al igual que los franceses, como una declaración de voluntad que produce efectos jurídicos perseguidos por los sujetos.

Segundo: El alejamiento, que posteriormente determinaría el total desprestigio del concepto francés del acto jurídico y su casi total abandono por los juristas de los diversos sistemas jurídicos latinos y que después da lugar a la enorme difusión y aceptación del concepto del negocio jurídico, se inició desde el mismo momento, en que los autores alemanes y por ende todos sus seguidores, empezaron a definir y entender el "negocio jurídico"4 ya no como una simple manifestación de voluntad, sino como un "supuesto de hecho", es decir, como una hipótesis prevista en abstracto por las normas jurídicas de una o más declaraciones de voluntad que producirán consecuencias jurídicas.

Por todo lo expuesto anteriormente, y como será fácil deducir, debemos señalar con toda claridad que desde nuestro punto de vista, es completamente inadecuado la definición del artículo $140^{\circ}$ del Código Civil por estar inspirada directamente en la concepción clásica del acto jurídico, completamente destruida y abandonada en la actualidad, por lo que debe eliminarse la definición de acto jurídico contenida en el artículo $140^{\circ}$, debiendo mantenerse únicamente la segunda parte referida a los requisitos de validez, que si nos parece pertinente.

Se trata de dos nociones elaboradas por diferentes sistemas doctrinarios con el mismo objetivo: establecer una teoría general sobre los actos humanos relevantes jurídicamente; igualmente se trata de dos nociones que coincidieron en un primer momento pero que posteriormente se alejaron.

Asimismo debemos añadirque si por tradición jurídica se ha decidido mantener en el nuevo Código Civil al igual que en el de 1936, la terminología francesa, ello no es impedimento para entender el acto jurídico del Código Peruano bajo la óptica del negocio jurídico, por tratarse justamente de dos nociones dirigidas al mismo objetivo conceptual, aún cuando han experimentado una evolución distinta. El enfoque adecuado debe sin duda al de los postulados de la teoría general del negocio jurídico, pues se trata de un tema íntimamente vinculado con la realidad social a la cual se aplica.

Tercero: Posteriormente nació la tercera corriente, la Teoría Preceptiva ${ }^{5}$ , entendiéndose que el negocio jurídico es un supuesto de hecho pero que contiene no simples declaraciones de voluntad sino un precepto social, es decir, una autorregulación de intereses privados socialmente útiles. Posteriormente se empezó a hablar de finalidades socialmente razonables o no absurdas como 
requisitos de validez de los negocios jurídicos atípicos. Como se podrá apreciar ya no se puede sostener más, sin peligro de riesgo absurdo, que el negocio jurídico es una declaración de voluntad destinada a crear, modificar, regular o extinguir relaciones jurídicas, pues se trata de una definición totalmente desactualizada y destruida por la evolución del propio concepto negocial; menos aún, nos podemos aferrar al concepto francés clásico del acto jurídico, por tratarse de una noción que se estancó definitivamente y que no supo adaptarse a los cambios políticos, sociales, filosóficos y económicos.

El enfoque adecuado debe ser sin duda el de los postulados de la teoría general del negocio jurídico. Ahora bien, dentro de las variantes respecto de la noción del negocio jurídico, existe total libertad para el jurista y el intérprete, dependiendo de su propia concepción.

\section{EL ACTO JURÍDICO 6}

La primera cuestión es resuelta por la ciencia del derecho, cuya tarea es definir el concepto de acto jurídico. La cuestión puede ser resuelta de distintas maneras por las diferentes escuelas científico- jurídicas.

La Teoría Pura del Derecho define al "acto jurídico" como un acto con el que una norma es establecida (hablando figurativamente, creada) o aplicada; y afirma que un acto es un acto creador o aplicador del derecho dentro del orden jurídico, esto es, si el acto en cuestión es establecido con fundamento de orden jurídico. Acto jurídico se define como la "manifestación de la voluntad que se hace con la intención de crear, modificar, transferir o extinguir un derecho". Acto jurídico es el acto humano voluntario o consciente y lícito, que tiene por fin inmediato establecer entre las personas relaciones jurídicas, crear, modificar, transferir, conservar o extinguir derechos. Acto jurídico es el instrumento con el cual se da concreta actuación a la autonomía privada. Autonomía privada quiere decir que los sujetos de derecho -dentro de los límites permitidos por el ordenamiento jurídico- tienen la libertad de regular sus intereses como mejor les parezca, regulación que está garantizada por el ordenamiento 7 .

El acto jurídico es el acto humano voluntario o consciente, que tiene por fin inmediato establecer entre las personas relaciones jurídicas, crear, modificar o extinguir derechos. El acto jurídico produce una modificación en las cosas o en el mundo exterior porque así lo ha dispuesto el ordenamiento jurídico.

Para que se dé el acto jurídico no basta con que haya un sujeto y un objeto con bastante capacidad, se necesita algo que los ponga en relación, estableciendo 
un lazo o un vínculo que los una, haciendo pasar la relación jurídica del estado de posibilidad al estado de existencia.

\section{NEGOCIO JURÍDICO}

Con el negocio el individuo no viene a declarar que quiere algo, sino que expresa directamente el objeto de su querer y ésta es una regulación vinculante de sus intereses en las relaciones con otros.

También, se considera como negocio jurídico: “La declaración o acuerdo de voluntades, con que los particulares se proponen conseguir un resultado, que el Derecho estima digno de su especial tutela, sea en base sólo a dicha declaración o acuerdo, sea completado con otros hechos o actos". Se destaca el resultado propuesto con la declaración de voluntad, ésta ha de seguir siendo estimada como el fundamento del negocio jurídico.

Pero el problema surge cuando se trata de precisar los últimos términos de la definición ¿La voluntad que constituye el alma del negocio jurídico, qué alcance debe tener?

Si de la ciencia pandectística pasamos a la época actual en que filósofos, juristas y sociólogos han contribuido a crear una teoría fundamental del Derecho, observamos claramente un progreso jurídico extraordinario. Pero a pesar de estas afirmaciones que hacemos como una introducción al estudio de la teoría del negocio jurídico en relación con la legislación romana, no podemos dejar de expresar nuestra creencia en la posibilidad de construir sobre los datos que nos proporcionan las fuentes romanas, una doctrina de esta clase, ajustada al espíritu de aquel pueblo.

Afirmamos que en los textos romanos encontramos soluciones prácticas y principios de aplicación positiva, aunque no teorías ni sistemas. Pero esto no es óbice para que, tomando como base esas soluciones y generalizaciones muy frecuentemente formuladas con independencia de las instituciones, puedan servir de fundamento a nuestros propósitos de elaboración de un sistema o teoría general del negocio jurídico a tono con las ideas de los romanos.

Esta "costumbre nacional" se ha visto reflejada, a nivel legislativo, en el propio Código Civil de 1984 en el artículo $140^{\circ}$, que textualmente define el acto jurídico como "la manifestación de voluntad productora de efectos jurídico", bien se trate de la creación, modificación, regulación o extinción de relaciones jurídicas. De esta manera, nuestro Código Civil ha consagrado 
a diferencia del Código de 1936, el concepto clásico francés del acto jurídico, elaborado por los primeros comentaristas del Código de Napoleón sobre las bases de Domat y Pothier ${ }^{8}$.

\subsection{Hecho jurídico}

Se denomina hecho jurídico en sentido amplio a un acontecimiento que tiene trascendencia en el ámbito del Derecho, es decir, se modifican ciertos estados jurídicos iniciales desde el punto de vista legal.

Una norma jurídica parte siempre de un presupuesto de hecho, para posteriormente regular las consecuencias que ello tiene en el área del derecho. El presupuesto de hecho de la norma es un hecho jurídico.

Es importante distinguir, dentro de los hechos jurídicos en sentido amplio, los llamados actos jurídicos y los hechos jurídicos en sentido estricto. Un hecho jurídico en sentido estricto no tiene por qué ser voluntario ni controlable por la persona, mientras que en un acto jurídico, la voluntad de la persona es esencial. Por lo tanto, todos los actos jurídicos son hechos jurídicos, pero no todos los hechos jurídicos son actos jurídicos.

Ejemplos de hechos jurídicos: la muerte, la promulgación de una Ley, una declaración de guerra o una catástrofe natural.

Ejemplos de hechos jurídicos que además son actos jurídicos: la comisión de un delito, la firma de un contrato o el otorgamiento del consentimiento matrimonial.

\subsection{Hechos natural es}

Para comprender la naturaleza del acto jurídico, debemos considerar en primer lugar los hechos, y especialmente a los hechos jurídicos.

Los hechos pueden tener su origen en la naturaleza o en el hombre, y en uno y otro caso, pueden producir efectos jurídicos. Si los producen, estamos ante hechos jurídicos, y en caso contrario, estamos ante hechos materiales.

\subsection{Hechos humanos}

Se ubican aquí los delitos y cuasidelitos. Si bien el delincuente actúa voluntariamente, no ejecuta un acto con el propósito de ser penado o de responder civilmente indemnizando los prejuicios; según algunos autores, 
necesariamente debe tener un contenido pecuniario o económico; sin embargo, las últimas tendencias han señalado que es perfectamente posible que el contenido sea de índole estrictamente moral, o en una posición ecléctica, que tenga un interés valuable indirectamente en dinero.

En lo que respecta a los actos contrarios a las buenas costumbres (concepto de carácter eminentemente variable y relativo), señala Avelino León que el acto jurídico que las contravenga adolecerá de objeto ilícito y consecuencialmente será nulo, de nulidad absoluta. Igual regla aplica en los casos de actos contrarios al orden público, lo cual es de toda lógica, pues un acto que atenta contra la moral, será también un ataque al orden público, es por ello que los conceptos de orden público y buenas costumbres se encuentran íntimamente relacionados.

En un sentido similar se pronuncia Luis Claro Solar, que relaciona los tres casos,"Por lo demás, la prohibición del acto o contrato por la ley tiene generalmente como fundamento las buenas costumbres contra las cuales pugna dicho acto o contrato, razones de orden e interés público que han llevado al legislador a establecer la prohibición".

\subsection{Hechos jurídicos voluntarios realizados con la intención de producir efectos jurídicos}

Son actos jurídicos, los que podemos definir como actos voluntarios por el hombre con la intención de crear, modificar, transferir o extinguir derechos. Ejemplo, creará derechos el contrato de compraventa, modificará derechos la novación, transferirá derechos la tradición, y extinguirá derechos el pago. Hay autores como Carlos Ducci que señalan que los hechos jurídicos solo se dividen en voluntarios e involuntarios. Los hechos jurídicos del hombre involuntarios son fruto de una actividad realizada sin la voluntad consciente. Tal acontece con los actos de los dementes y los infantes. Los hechos jurídicos del hombre voluntarios son aquellos que la ley atribuye un efecto jurídico no querido o distinto del perseguido por el autor. Se subdividen en lícitos e ilícitos.

\subsection{El hecho y acto jurídico, su relación con el negocio jurídico}

Si se concibe el derecho privado como un sistema de derechos subjetivos, surge la cuestión primordial de estudiar de qué manera nacen éstos a la vida y cuáles son los hechos que tienen la virtualidad de crearlos. Tal estudio exige la consideración de los llamados hechos y negocios jurídicos. 
Los jurisconsultos romanos, con su proverbial espíritu práctico y su característica hostilidad hacia la abstracción, no construyeron una teoría general de los hechos y negocios jurídicos, sino que fueron considerando en los casos concretos que se les presentaban, qué situaciones merecían ser protegidas por medio de acciones y en qué circunstancias debía reconocerse a una determinada persona una facultad para actuar respecto de una cosa o de otra persona también determinada.

La dogmática moderna, recogiendo los principios básicos suministrados por la jurisprudencia romana, elaboró la teoría del negocio jurídico, cuya paternidad se atribuye al jurista alemán Gustavo Hugo. Con los antecedentes romanos, que son los que particularmente nos interesan, y con los resultados de las construcciones doctrinarias actuales, abordaremos el tema de los hechos y negocios jurídicos.

La norma jurídica, considera como relevante y digno de valoración exclusivamente su carácter de ser fenómenos naturales, lo cual significa que sus efectos jurídicos se producen por imperio de la ley (ope legis, ipso jure). Ahora bien, cuando el hecho jurídico no es producido por factores naturales, sino por el actuar del hombre, por un acto de voluntad del sujeto, estamos en presencia del acto jurídico, que podemos definir diciendo que es el acto voluntario susceptible de producir el nacimiento, la modificación, la transformación o la extinción de los derechos.

En el Perú, está previsto en el artículo $140^{\circ}$ del Código Civil, en forma expresa noción de acto jurídico: elementos esenciales: "El acto jurídico es la manifestación de voluntad destinada a crear, regular, modificar o extinguir relaciones jurídicas. Para su validez se requiere: 1) Agente capaz; 2) Objeto física y jurídicamente posible; 3) Fin lícito y; 4) Observancia de la forma prescrita bajo sanción de nulidad."

Son requisitos de existencia: la voluntad, el objeto, la causa, las solemnidades en aquellos actos que la ley lo exige.

Son requisitos de validez: la voluntad exenta de vicios, la capacidad, el objeto lícito, y la causa lícita9.

${ }^{10}$ Artículo $141^{\circ}$ del Código Civil.- La manifestación de voluntad puede ser expresa o tácita. Es expresa cuando se realiza en forma oral o escrita, a través de cualquier medio directo, manual, mecánico, electrónico u otro análogo. Capacidad como elemento de validez del acto jurídico. 
Negocio jurídico es una manifestación de voluntad que tiene por objeto la producción de ciertos y determinados efectos jurídicos.

\section{Las formalidades en los actos jurídicos ${ }^{11}$}

Los actos jurídicos, en general, pueden ser formales o no formales. Son formales aquellos actos jurídicos para cuya existencia o validez es necesaria la manifestación de ciertos caracteres externos, en vista a producir plenos efectos jurídicos. Ejemplo de esto son los contratos solemnes, que requieren de una solemnidad propiamente tal, o los contratos reales, que requieren de la entrega de una cosa.

Las formalidades, tal como las reconoce la doctrina, pueden ser:

- Formalidades objetivas o ad-solemnitatem: se refiere a aquellas formalidades que constituyen requisito de existencia o validez del acto en cuestión y ante cuya omisión el acto es nulo, inexistente o no produce efecto jurídico alguno. Por ejemplo, en la mayoría de los países, la compraventa de bienes raíces debe celebrarse en escritura pública, sin la cual se entiende que la venta es nula. Dichas solemnidades se establecen en consideración a la naturaleza del acto, dada la importancia que el determinado negocio jurídico tiene para el ordenamiento jurídico nacional.

- Formalidades habilitantes: son aquellas formalidades establecidas en consideración de las personas incapaces o ausentes, en vistas de proteger su patrimonio con ciertas cortapisas legales que impiden a sus representantes disponer libremente de su patrimonio. Tal es el caso, de las restricciones de los guardadores de la venta de bienes raíces de sus pupilos, la que, en la mayoría de los países, debe hacerse en pública subasta previa autorización del juez competente. Su omisión implica la nulidad del acto en cuestión.

- Formalidades de prueba o ad probationem: aquellos requisitos externos al acto jurídico que se exigen en consideración a la acreditación formal de un acto ante la sociedad o las autoridades. Por regla general, se traduce en la escrituración del determinado acto, como es en el caso de los contratos de trabajo, donde es de interés del legislador que dichos actos se mantengan escriturados y/o registrados, en protección de los trabajadores. Su omisión jamás acarrea la nulidad, sino que formas distintas de ineficacia de los actos jurídicos, tales como la inadmisibilidad de la prueba testimonial.

- Formalidades de publicidad: aquellas formalidades destinadas a dar 
publicidad al determinado acto jurídico y que por regla general se traducen en la inscripción del negocio en un registro público, de modo que todas las personas tengan acceso al conocimiento de su contenido y efectos. Su violación acarrea, como norma general, la inoponibilidad del acto frente a terceros.

Clases de actos jurídicos en sentido estricto. Se subdistinguen éstos en actos semejantes a los negocios y actos no semejantes a los mismos ${ }^{12}$.

a) A ctos semejantes a los negocios jurídicos. Son actos semejantes a los negocios, aquellos en los que si bien el efecto se produce ex lege, sin embargo, la realidad es que suelen ejecutar con conciencia de la misma y normalmente con la intención de producirlo. Es decir, aunque su producción no se basa en que sea querido, el agente lo suele querer.

A su vez, dentro de estos actos semejantes a los negocios jurídicos cabe señalar diversos tipos:

- Exteriorización de la voluntad, que la ley dota de efectos jurídicos pero sin que estos correspondan al contenido de voluntad que se exterioriza, ni ésta pueda modificarlos ${ }^{13}$.

La diferencia, entre esas exteriorizaciones constitutivas de actos semejantes a los negocios y las declaraciones de voluntad está en que a éstas el efecto jurídico corresponde al contenido de la voluntad declarada (voluntad que regula esos efectos y que - como regla - puede modificar, en los casos concretos, los que la ley estableció en abstracto) y en aquellas no, porque en éstas lo importante es la voluntad declarada, mientras que en aquellas, aunque consisten también en manifestar una voluntad, lo que importa no es tanto lo que se manifiesta querer, sino el haberlo manifestado voluntariamente. Por ejemplo, si en una declaración de voluntad se intuye heredero, el efecto jurídico ex volúntate consiste en el llamamiento a la herencia del instituto, efecto cuyo contenido corresponde a la voluntad que se declaró. Mientras que, diferentemente en la intimación que el acreedor dirige al deudor para que éste cumpla la obligación - intimidación que es una exteriorización de voluntad constitutiva de un acto semejante a los negocios - el efecto jurídico que se produce - en el caso de la deuda no cumpla - es el quedar éste constituido en mora (Código Civil, artículo $100^{\circ}$ ), efecto que no corresponde al contenido volitivo que el acreedor exteriorizó, pues éste manifestó querer el cumplimiento de la obligación, cosa que es distinta de la constitución en mora. 
Ello ocurre así porque los efectos del hecho - contrariamente al derecho, que sucede por necesidad jurídica - pueden no tener lugar (así, si el deudor hace caso omiso de la intimación, no se produce el efecto de hecho que el acreedor manifestó querer: el cumplimiento). Por eso, el ordenamiento dota a la intimación de unos efectos jurídicos distintos de los que el acreedor expresó querer. Este puede - independientemente de esto tener conciencia de ellos y desearlos, puede también haber intimado al deudor precisamente para que se produjeran, puede además, manifestar explícitamente que los persigue o bien puede hacer todo lo contrario diciendo no desear su producción. En cualquier caso sus manifestaciones en orden a querer o no querer la constitución en mora del deudor, son indiferentes para la ley que produce simplemente por la intimación. Otros ejemplos de exteriorizaciones de voluntad constitutivas de actos jurídicos semejantes a los negocios son numerosos requerimientos, reclamaciones, conminaciones, negativas, etcétera. Así, el hecho al tutor para que inscriba en el inventario los créditos que tenga contra el pupilo (Código Civil, artículo $267^{\circ}$ ), la de los acreedores a que se haga sin su concurso, la división de la cosa común (Código Civil, artículo 403º ), la dirigida al tercer poseedor de la finca hipotecada para que la desampare, la del propietario a contribuir al seguro del precio, sujeto a usufructo (Código Civil, artículo $518^{\circ}$ numeral 2), etcétera.

- Exteriorizaciones de acontecimiento espirituales que no son su voluntad, así exteriorizaciones de una creencia o de un conocimiento convicción. Opinión, sentimiento, etcétera, no se declara voluntad alguna. No hay duda de que el efecto jurídico no se produce ex volúntate. Que accidentalmente el sujeto manifieste, determina voluntad, favorable o no a los afectos jurídicos, es perfectamente inoperante. Los casos más típicos son quizás, las llamadas declaraciones de ciencia, uno de cuyos ejemplos es el reconocimiento de un hijo natural (Código Civil, artículo $129^{\circ}$ y siguientes).

Cuando se trata de manifestaciones dirigidas a otra persona se habla de notificaciones.

A los actos semejantes a los negocios - cuando falten normas específicas dictadas para ellos - serán aplicables las referentes a las declaraciones de voluntad en tanto los justifique la analogía de unos y otras. La analogía no sólo existe cuando el elemento contemplado en ambos sea en sí diverso, sino tampoco, cuando tiene valor diferente o desempeña función distinta en un caso respecto de otro. 
En los singulares supuestos será a veces preciso aclarar hasta donde es pertinente el argumento de analogía o si el que procede es al contrario.

\section{b) A ctos no semejante a los negocios ${ }^{14}$}

Junto a los actos semejantes a los negocios, la doctrina española más moderna suele situar, siguiendo a un autorizado sector de la doctrina alemana otro grupo de actos llamados reales, que conjuntamente con aquellos integran la categoría de actos en sentido estricto. Nosotros sin embargo; preferimos agruparlos bajo la calificación de "no semejantes a los negocios", que es de mayor amplitud. En ellos, el sujeto al ejecutar el acto, no suele perseguir los efectos que el ordenamiento fija ex lege, a diferencia de lo que ocurre en lo semejante a los negocios, en los que si suelen hacerlo.

La conducta que el agente observa va encaminada a un resultado de hecho material generalmente -, o bien siendo voluntario, lo produce sin pretenderlo, pero lo cierto es que el conjunto formado por la conducta humana y el resultado de hecho, es a su vez considerado por la ley como búsqueda de un efecto jurídico ${ }^{15}$.

Ejemplos tenemos en la especificación (Código Civil, artículo 383 $) \cdot{ }^{16}$

Negocio jurídico ${ }^{17}$. Definición: el negocio jurídico es el acto de autonomía privada de contenido preceptivo con reconocimiento y tutela por parte del orden jurídico.

La formulación conceptual que mejor representa al negocio jurídico es la propuesta de acto de autonomía privada de contenido preceptivo con reconocimiento y tutela por parte del orden jurídico, por representar esta fórmula su estructura, función y resultado.

La consideración del negocio jurídico como acto de autonomía privada - como ejercicio del poder reconocido en virtud de ese principio - resalta su estructura; el contenido preceptivo de ese acto - como medio de organización por los particulares de sus propios intereses - destaca su función; y la intervención del orden jurídico - como valoración dada por la norma a ese acto - resalta su contenido.

El negocio jurídico como cauce de exteriorización del principio de autonomía privada en su faceta del poder de creación, modificación o extinción de relaciones jurídicas y conformación o autorregulación de las mismas, es el 
instrumento práctico con el que cuentan los particulares para el efectivo ejercicio del poder reconocido en virtud de dicho principio.

El precepto negocial, como expresión del contenido preceptivo del negocio, representa al conjunto de reglas de conducta establecidas por las partes para regular una relación jurídica por ellos mismos creada, con eficacia vinculante para sus otorgantes desde su creación; es decir, como regulación vinculante de intereses dispuesta para el futuro por los propios interesados. Esta eficacia vinculante - con refrendo positivo a través de la fórmula fuerza de ley - no significa la atribución de normatividad jurídica al precepto negocial, sino vinculante como determinante de una conducta o de un comportamiento concreto para los sujetos de una relación.

La intervención el orden jurídico en el proceso formativo del negocio se despliega desde una doble vertiente; por un lado mediante un reconocimiento del principio de autonomía privada, previo genérico e independiente de la formación del negocio, y por otro lado, mediante un reconocimiento posterior, por el que perfeccionado el negocio y valorado positivamente se integra dentro del sistema negocial, atribuyendo, colmando o modificando los efectos jurídicos. "Dogmática y formulación conceptual del negocio jurídico".

En el caso del negocio jurídico típico no cabe duda que exista el valor de la utilidad social, que justifica la existencia de los mismos a nivel legal. La utilidad social determina que el ordenamiento jurídico se vea en la imperiosa necesidad de elevar la figura del negocio jurídico, que se práctica en el ámbito social, al rango de negocio jurídico a través de su incorporación a un determinado supuesto de hecho.

Sin embargo, el problema se manifiesta en toda su amplitud en el campo de los negocios jurídicos atípicos, que por no estar contenidos en supuestos específicos, carecen de respald o de un tipo legal que justifique su existencia y regulación legal.

Como es sabido, en estos negocios también cumple el requisito de la necesidad de un supuesto de hecho específico, es decir, un supuesto rehecho que no es un tipo legal sino únicamente un esquema legal genérico.

Pues bien, para los tratadistas que se acogieron a la concepción preceptiva, el supuesto de hecho genérico tenía como única exigencia el de la utilidad social, de forma tal que entendían que cualquier autorregulación de intereses privados que estuviera orientada a la consecución de una finalidad socialmente 
útil, merecía la calificación de negocio jurídico para adaptarse al supuesto de hecho genérico.

De esta manera, se entendía que todos los negocios jurídicos atípicos, eran todos aquellos dirigidos a una función socialmente útil, que como tal, se encontraba tipificada, ya no por la norma jurídica, sino por la misma realidad social; es así como se llega a la tipicidad social en contraposición a la tipicidad legal, señalando que en los negocios típicos es legal y en los atípicos debía entenderse siempre la existencia de una tipicidad social.

Con este cambio en la concepción radical de la utilidad social, el concepto preceptivo del negocio jurídico se ha adaptado a los tiempos modernos y actuales, en los que el individuo juega un rol fundamental dentro del ámbito social, sin dejar de lado en ningún momento el valor social de todo negocio jurídico y sin desconocer que además del significado social, todo negocio supone siempre una valoración del ordenamiento jurídico, pues en principio el negocio jurídico es siempre un supuesto de hecho.

De esta forma ha quedado abandonada, para siempre, las concepciones individualistas de los actos de la persona que producen consecuencias legales, desconocían la intervención del ordenamiento jurídico en su función ordenadora, valorativa y dejaban de lado abiertamente el significado social de dichos actos, limitándose a construir concepciones meramente artificiales y abstractas de los mismos.

Siendo ello así, ya no se puede sustentar más, sin peligro y riesgo de ser absurdo, que el negocio jurídico es una declaración de voluntad destinada a crear, modificar, regular o extinguir relaciones jurídicas, pues se trata de una definición totalmente desactualizada y destruida por la evolución del propio concepto negocial; menos aún, nos podemos aferrar al concepto francés clásico del acto jurídico, por tratarse de una noción que estancó definitivamente y que no supo adaptarse a los cambios políticos, filosóficos y económicos.

Se ha pretendido señalar que el acto jurídico y el negocio jurídico no son figuras distintas. Grave error, ya que el acto jurídico de la doctrina francesa no es igual al negocio jurídico de la doctrina alemana.

Federico de Castro y Bravo señala que el negocio jurídico es como para todos los demás un supuesto de hecho, pero un supuesto de hecho diferente, porque contiene en si mismo normas jurídicas, tiene un contenido normativo. La noción causa se encuentra íntimamente vinculada con la del negocio jurídico 
y que dependerá de nuestra concepción del negocio jurídico lo que debe entenderse por causa negocio.

Por todo lo expuesto anteriormente y como será fácil deducir, debemos señalar con toda claridad que es completamente inadecuado la definición del artículo $140^{\circ}$ del Código Civil, por estar inspirada en la concepción clásica del acto jurídico, completamente abandonada en la actualidad, por lo que se debe optar por la concepción negocial, que es seguida mayoritariamente en la doctrina y por la jurisprudencia de un determinado sistema jurídico, pues se trata de un tema íntimamente vinculado con la realidad social a la cual se aplica.

En tal sentido, compartiendo con la posición de Lizardo Taboada Córdova debe eliminarse la definición del acto jurídico.

1 Taboada Córdova, Lizardo. Conferencia: La teoría del acto jurídico y el concepto del negocio jurídico dentro del Código Civil Peruano. Lima-Perú: septiembre, 1999.

Ibidem.

Ibidem.

Ibidem.

Ibidem.

Kelsen, Hans. ¿Qué es un acto jurídico? Isinomia, Nº4. Abril, 1996. Pág. 66

Torres Vásquez, Aníbal. Acto Jurídico. 2da. Edición. Ideosa: Lima, 2001. Pág. 63.

8 Taboada Córdova, Lizardo. Conferencia: La teoría del acto jurídico y el concepto del negocio jurídico dentro del Código Civil Peruano.

9 Universidad de los Lagos, Campus Chinquihue, Puerto Montt.

$10\left(^{\star}\right)$ Artículo modificado por el artículo $1^{\circ}$ de la Ley $N^{\circ} 27291$, publicada el 24-06-2000, cuyo texto es el siguiente: Manifestación de voluntad “La manifestación de voluntad puede ser expresa o tácita. Es expresa cuando se realiza en forma oral o escrita, a través de cualquier medio directo, manual, mecánico, electrónico u otro análogo. Es tácita cuando la voluntad se infiere indubitablemente de una actitud o de circunstancias de comportamiento que revelan su existencia. No puede considerarse que existe manifestación tácita

12 Artículo $142^{\circ}$.- El silencio: "El silencio importa manifestación de voluntad cuando la ley o el convenio le atribuyen ese significado".

13 Forma del acto jurídico- Artículo $143^{\circ}$.- Libertad de forma: "Cuando la ley no designe una forma específica para un acto jurídico, los interesados pueden usar la que juzguen conveniente."

Artículo $144^{\circ}$.- Forma ad probationem y ad solemnitatem: "Cuando la ley impone una forma y no sanciona con nulidad su inobservancia, constituye sólo un medio de prueba de la existencia del acto."

12 La terminología no es, sin embargo, uniforme, ni tampoco esa bipartición se acepta por todos. Es más, la corriente en nuestra actual doctrina es contraponer los "los actos reales" a los "actos semejantes a los negocios jurídicos". A parte de eso, hay que tener en cuenta que como no toda declaración de voluntad constituye de por sí un negocio jurídico (sino que precisa de otros elementos), en vez de hablar de actos semejantes o no a los negocios jurídicos sería más exacto de hablar de actos semejantes o no a las declaraciones de voluntad. Sin embargo, con esta advertencia conservamos la terminología por razón de ser usual. Academia de la Magistratura, Programa de formación de aspirantes. Módulo Derecho Civil, sobre Manuel Albaladejo. Negocio Jurídico. Capítulo: El Hecho Jurídico. Lima, 1999. Pág. 37.

13 Otros hablan de "exteriorizaciones de voluntad parecidas a los negocios" o "de manifestaciones de voluntad carentes de carácter negocial" o de "manifestaciones de voluntad no decisivas" (porque el 
contenido de la voluntad manifestada no es decisivo para el efecto jurídico) o de "manifestaciones de voluntad irrelevantes por la voluntad manifestada", etcétera.

14 Violeta Gustale.- "El origen de los negocios jurídicos"

violeta.gustale@idea.org.py www.monografias.com

15 Cuando el derecho toma en cuenta sólo el resultado de hecho con omisión de que sea provocado por la conducta humana, no estamos - como ya dijimos - en presencia de un acto jurídico, sino de un hecho natural.

16 Al que piense que convirtiéndose también el loco en dueño de la obra en la que emplea materia ajena, es irrelevante la conducta humana.

17 De Wikipedia, la enciclopedia libre. 